\title{
Ontologia do limite
}

\author{
RAQUEL DE AZEVEDO *
}

* Doutoranda em Filosofia na PUC-Rio

raquelazevedo@gmail.com
RESUMO Numa inversão da pergunta lévi-straussiana acerca da mitologia ameríndia, trata-se aqui de investigar de que modo o pensamento ocidental incorpora o processo catastrófico de colonização do continente americano. A resposta a essa pergunta passa, segundo minha hipótese, pela estrutura de pensamento que se inaugura com a Utopia de Thomas More, diretamente influenciada pelos relatos de viagem de Américo Vespúcio. A divisão interna do livro de Thomas More, segundo a qual a ilha de Utopia surge como um enclave no interior da Inglaterra do século XVI, permite uma aproximação entre a literatura utópica e a metafísica leibniziana. Este trabalho procura mostrar que o pensamento utópico se constitui como um caso particular da teoria dos infinitos mundos possíveis de Leibniz. Enquanto Thomas More opera com um único mundo possível em oposição ao mundo realmente existente, Leibniz pensa a ordenação do mundo a partir dos infinitos possíveis, compondo uma teoria geral do pensamento distópico.

PalaVRas-chaVe Colonização, Utopia, Thomas More, Leibniz, infinitos mundos possíveis.

ABSTRACT In a reversal of the Levi-Straussian question about Amerindian mythology, this work aims to investigate how Western thought incorporates the catastrophic process of American colonization. The answer to this question goes through, according to my hypothesis, the thought structure that begins with Thomas More's Utopia, a book directly influenced by Amerigo Vespucci's travel reports. The inner division of Thomas More's book, in which the island of Utopia emerges as an enclave inside the sixteenth-century England, allows an approximation between Utopian literature and Leibnizian metaphysics. This work attempts to show that utopian thought is a particular case of Leibniz' theory of the infinite possible worlds. While Thomas More operates with a single possible world in opposition to the really existing world, Leibniz thinks the ordering of the existing world from the infinite possible ones, composing a general theory of dystopian thought.

KEYWORDS Colonization, Utopia, Thomas More, Leibniz, infinite possible worlds. 
Nem bem haviam se completado 50 anos do início da colonização europeia em território americano e um mito colhido entre os Tupinambá por André Thevet, a quem Lévi-Strauss atribui, ao lado de Jean de Léry, as origens da disciplina de Antropologia Social, revelaria que os índios já haviam incorporado o motivo do homem branco às suas narrativas. O evento catastrófico da chegada dos europeus havia sido assimilado na condição de termo da estrutura de pensamento ameríndia. Na hipótese de Lévi-Strauss, isso se deve ao fato de serem os mitos uma forma de ordenação progressiva dos seres e das coisas em uma série de bipartições, de modo que as partes resultantes em cada etapa se revelam sempre desiguais. É do desequilíbrio dinâmico presente no interior das dualidades (tais como o criador e a criatura, os índios e os brancos, os concidadãos e os inimigos, os bons e os maus, os fortes e os fracos) que o pensamento ameríndio retira seu modo de funcionamento. O que os mitos dizem, argumenta Lévi-Strauss em História de Lince, é que os pólos em que se organizam os fenômenos nunca poderão ser gêmeos e são as distâncias diferenciais em sequência “que colocam em movimento a máquina do universo" . Ora, nenhum desequilíbrio poderia parecer mais profundo aos índios do que aquele entre eles e os brancos. Nesse sentido, tudo se passa como se o lugar dos brancos estivesse marcado em vazio em um sistema de pensamento que opera com um estreitamento progressivo das oposições. De uma oposição entre contraditórios passa-se a uma oposição entre contrários e, então, a uma diferença de grau. Ou seja, “[d]e uma oposição inicial entre humano e não humano passar-se-á, por transformação, àquela entre humano e animal, depois para uma outra, ainda mais fraca, entre graus desiguais de humanidade (ou de animalidade)" O grau mínimo da diferença é, para Lévi-Strauss, o caso dos gêmeos e o índio e o branco são uma das formas da gemelaridade impossível da mitologia ameríndia.

A pergunta a que este trabalho se propõe, no entanto, é uma inversão do problema lévi-straussiano, ou seja, trata-se de investigar de que modo o pensamento ocidental incorpora o processo catastrófico de colonização do continente americano. A res-

1 LÉVI-STRAUSS, C, 1993, p. 66.

2 Ibid., p. 172. 
posta a essa pergunta passa, segundo minha hipótese, pela estrutura de pensamento que a Utopia de Thomas More inaugura com a descrição da ilha pelo navegante Hitlodeu - palavra de origem grega que significa “mercador de disparates”. À diferença da república ideal de Platão que se caracteriza por um aspecto diacrônico, a Utopia de More, publicada em 1516 sob influência direta dos relatos de viagem de Américo Vespúcio, é uma experiência sincrônica. A ilha de Utopia não é um estado futuro das sociedades europeias, é um espaço concomitante a elas. Estamos diante de uma operação lógica que cria, pela ficção, uma ordenação social através de um deslocamento espacial e não temporal. Utopia é a espacialização daquilo que nos tratados políticos sobre a república ideal se dá no tempo.

A própria divisão interna do livro sugere que a ilha surge como um enclave no interior da Inglaterra do século XVI, ou seja, enquanto o Livro I se dedica a identificar os desdobramentos de um processo histórico de expropriação dos produtores diretos, de dissolução da propriedade privada baseada no trabalho individual, o Livro 2 apresenta uma sociedade constituída a partir de uma bricolagem entre elementos da pólis grega, dos monastérios medievais, da Reforma e do modo de produção inca, segundo Fredric Jamenson em Archaelogies of the future. A relação entre os dois livros parece nos remeter a uma oposição entre aquilo que é realmente existente e sua variação possível, ainda que, ironicamente, o Livro I, pólo associado ao real, se valha de uma estrutura clássica às narrativas distópicas, a inversão entre o homem e o animal, ao descrever a transformação social da região rural inglesa através da imagem de ovelhas que devoram os homens. Por outro lado, o Livro 2 investiga, nos termos de Christopher Kendrick no artigo “More’s Utopia and uneven development”, uma combinação imaginária de modos de produção, cuja emergência está associada à visão caleidoscópica de uma classe privada de seus meios de vida. Ou seja, o Livro 2 traz a marca da utopia, segundo Roland Barthes em Sade, Fourier, Loyola, na medida em que narra uma forma de organização da vida cotidiana, e o Livro 1 se vale de um enredo usual em distopias para descrever o processo de acumulação primitiva.

Mas o problema associado aos dois segmentos em que se divide a Utopia de More é o da transformação de um em outro. Como o processo histórico de cercamento dos campos, que consiste no fim da propriedade segundo a qual o trabalhador mantém controle de todo processo produtivo e do produto de seu trabalho, se comunica com a solução estética que tanto se assemelha, segundo Jameson em Archaelogies of the 
future, à escrita de constituições e de manifestos? Ou, dito de outra forma, como o mundo se comunica com seu enclave? A própria ilha traz a marca dessa separação geopolítica do espaço na medida em que a primeira ordem do rei Utopos após a conquista da península fora a construção de um canal que desligasse o território utópico do continente. Se é possível conceber nessa geografia imaginária mais do que uma sátira à Inglaterra, mas um esforço de construção de um objeto autônomo e auto-referencial, “a universe that doesn't fall apart two days later”, como diria Philip K. Dick no título de seu famoso artigo de 1978 sobre o conteúdo de suas distopias, o canal que separa a ilha utópica do continente, o Livro 2 do Livro 1, é uma variação no regime de propriedade. Para dar conta dessa modificação, o esforço sincrônico da Utopia exige a elaboração de uma representação totalizante, ao contrário dos Estados não-existentes cujo surgimento está associado a um desenvolvimento diacrônico das condições atuais. É nesse sentido que Thomas More combina, na descrição do modo de vida da ilha, o modelo inca de um sistema de poder central em uma república igualitária aos monastérios medievais, os quais funcionavam como um enclave em relação à sociedade agrícola feudal. Trata-se de uma bricolagem de instituições decadentes, visto que tanto o império inca quanto o monastério estão em processo de dissolução na época de More. A imaginação utópica parece, assim, medir o grau de entropia de uma organização social, ou seja, o recurso a instituições como o monastério e as terras comuns é um indicativo da irreversibilidade (que não se confunde com necessidade) das transformações associadas à chamada acumulação primitiva. O esforço associado à imaginação da ilha de Utopia seria um fenômeno dissipativo e a bricolagem que o caracteriza se faz exatamente com as relações sociais perdidas.

O pensamento utópico surge, portanto, da torção de um elemento da realidade realmente existente, o regime de propriedade, de modo que a sincronia entre os dois mundos, um real e o outro possível, parece colocá-los num mesmo plano, o do livro de Thomas More. Minha hipótese é que a estrutura lógica em que se organizam as duas partes da Utopia é um caso particular da teoria de Leibniz acerca dos infinitos mundos possíveis, em que não apenas uma, mas infinitas variações se opõem à sequência de contingências que compõe o mundo existente, sendo todas inferiores em perfeição, em essência e em diversidade em relação ao mundo atual. A Utopia seria, assim, um caso particular das distopias com que se caracterizam os mundos preteridos por Deus, menos ricos em fenômenos. Com sua tendência ao nivelamento e à vio- 
lação do princípio dos indiscerníveis, segundo o qual não podem existir duas coisas que difiram apenas numericamente, as utopias figurariam nos níveis mais baixos da pirâmide com que Leibniz exprime a ordenação dos infinitos mundos possíveis tais como são concebidos no intelecto divino.

Entre os $\S 405$ e 417 dos Essais de Théodicée, Leibniz cria um experimento ficcional em que descreve a disposição desses mundos em cômodos do palácio de Júpiter. No palácio dos destinos, o visitante conduzido por Palas Atena, filha de Júpiter, veria uma sequência de mundos que contém todos os casos obtidos pela variação de determinadas circunstâncias e de suas consequências. Mas não só. Mais do que abraçar a totalidade dos mundos possíveis, a sabedoria de Deus penetra-os, compara-os, pesa-os uns contra os outros para estimar os diferentes graus de perfeição das infinitas séries possíveis do universo. O mais perfeito dos mundos possíveis se localiza no pico da pirâmide e sua base se estende ao infinito. Tal configuração explicita que há uma prioridade de natureza nessas operações do intelecto divino, ou seja, há uma ordem entre todas as combinações possíveis, mas não há nelas qualquer prioridade de tempo. Deus vê de uma só vez todas as sequências de mundo possíveis.

O palácio dos destinos se caracteriza, portanto, pela sincronia e pela variação infinitesimal de um cômodo para outro. Minha hipótese é que a ordenação dos infinitos mundos possíveis na narrativa leibniziana tem a mesma estrutura do cálculo diferencial, ou, dito de outra forma, a biblioteca de distopias que encontramos no palácio de Júpiter é uma expressão ficcional da derivada. Mas o que, de fato, significa comparar o mundo atual e os infinitos possíveis a ele associados ao comportamento de uma curva no plano cartesiano? Significa dizer que as retas tangentes de uma curva qualquer são análogas às cenas de um mundo em que Judas não trai, Adão não peca ou César não atravessa o Rubicão, isto é, cenas de um mundo de proposições contraditórias com o mundo em que Judas trai, Adão peca ou César atravessa o Rubicão, respectivamente. Pode-se dizer que as tangentes são a representação bidimensional das distopias, ou, o que parece ser o intento leibniziano com o palácio dos destinos, os infinitos mundos possíveis são a ordenação tridimensional do cálculo infinitesimal das diferenças que Leibniz elabora na década de 1670.

A transformação que o cálculo diferencial representa em relação ao método de exaustão de Arquimedes passa fundamentalmente pela capacidade de operação com os in- 
finitesimais, os zeros relativos, como Leibniz os denominou na carta a Guido Grandi de 1713. A geometria grega não possuía definições precisas de comprimento, área e volume, de modo que o significado dessas quantidades era expresso através de relações de proporção. Isso significa que em vez de se perguntar qual a área de um círculo, Eudoxo, que antecedeu Arquimedes, investiga a razão entre as áreas de dois círculos através de quadrados de mesmo diâmetro, explica Carl Boyer em The history of the calculus and ist conceptual development. O método da analogia revela toda sua potência no procedimento de inscrição de um polígono regular no interior de um círculo e de divisão sucessiva de seus lados, a fim de que se obtenha uma figura que coincida com o círculo e que possa, assim, exaurir sua área. Nessa operação, o conceito de limite é puramente geométrico e não numérico, algo que só seria possível a partir do estudo dos números irracionais. Tendo como fundamento as noções de continuidade do espaço, o método de exaustão se depara com a dificuldade de o polígono inscrito poder se aproximar do círculo o quanto se queira sem jamais coincidir com ele, o que implicaria um termo final no processo de subdivisão de seus lados. No estudo da área de um segmento parabólico, Arquimedes mostraria, a partir de um argumento baseado na reductio ad absurdum, que uma razão maior ou menor do que a equivalência entre o polígono e o segmento de curva era inconsistente com o princípio de que a diferença poderia ser tão pequena quanto se desejasse.

Dado que a geometria grega se interessava mais pela forma do que pela variação, não há na matemática antiga a ideia de correspondência entre curva e função ou tampouco a definição da tangente através do conceito de limite. A ideia de construção mecânica de uma curva ocorreria a Leibniz através do estudo das propriedades do triângulo aritmético de Pascal, como explica Marc Parmentier na introdução aos artigos publicados por Leibniz na Acta Eruditorum. Seu desafio foi transpor as diferenças finitas entre os elementos do triângulo para as diferenças infinitesimais entre as ordenadas de uma curva. O resultado é a definição da tangente como a razão de diferenças das ordenadas e das abscissas à medida que se tornam infinitamente pequenas, enquanto a integral é dada pela soma das ordenadas para intervalos infinitesimais nas abscissas. Leibniz mantém a propriedade do triângulo de Pascal de serem as operações de soma e diferenciação mutuamente inversas, mas a diferenciação se torna o caso mais fundamental e a integral, sua posição invertida. 
Se seguimos a hipótese de que o cálculo da tangente de uma curva é análogo à disposição dos infinitos mundos possíveis no palácio de Júpiter, vemos que o que garante no interior de cada mundo a própria condição de mundo, ainda que nunca venha a se realizar, é essa forma muito específica de operar com o infinitesimal, não mais pelo acréscimo indefinido de partes cada vez menores, mas pela transformação do infinitamente pequeno em um termo operacional. Ou seja, a relação entre o Livro 1 e o Livro 2 da Utopia de Thomas More pode ser pensada como uma relação diferencial, em que uma mínima variação gera um máximo desvio. É nesse sentido estrito que a distopia é uma experiência mental limite: o limite matemático que está na definição do cálculo da tangente de uma curva é aquilo que faz da distopia um mundo.

Há, porém, outra hipótese acerca da coincidência entre uma curva qualquer e a série de elementos contingentes que compõe um mundo, uma hipótese que toma essa curva como uma lente ou um espelho que gera focos de perspectiva fora dela, ou, como diria Gilles Deleuze em A dobra, que considera um ponto não como um ponto de inflexão da curva, mas como um lugar, uma posição, um foco fora da curva em que se encontram as retas perpendiculares às tangentes. Este lugar é o ponto de vista, uma posição que permite seriar a variação, ordenar os diferentes casos. Um exemplo de ponto de vista sobre a variação é o das cônicas. A ponta de um cone é o ponto de vista ao qual são reportados o círculo, a elipse, a parábola, a hipérbole e a reta, conforme o plano de corte do cone. Significa dizer que aquilo que um ponto de vista fornece é sempre uma variante, ou, nas palavras de Deleuze, que em um mundo que perdeu todo centro, o objeto só existe através de suas metamorfoses. Passa-se, assim, da curvatura variável ao foco da curvatura, ou, como diz Deleuze, da inflexão à inclusão. Ou seja, a série infinita das curvaturas ou inflexões é o mundo e o mundo inteiro está incluído na alma sob um ponto de vista.

A pergunta que se faz Deleuze a respeito da passagem da curva ao seu foco de perspectiva é saber por que é preciso partir do mundo ou da série, por que se vai das inflexões às inclusões no sujeito. Como seria essa operação possível se o mundo só existe nos sujeitos que o incluem? O mundo está na mônada, cada mônada inclui toda série de estados do mundo, mas nenhuma contém a razão da série, a lei das curvaturas da qual todas elas resultam e que lhes permanece exterior como princípio de seu acordo. Passa-se do mundo ao sujeito, diz Deleuze, “ao preço de uma torção que faz com que o mundo só exista atualmente nos sujeitos, mas que faz também com que todos 
os sujeitos sejam reportados a esse mundo como à virtualidade que eles atualizam"3. O jogo no país dos possíveis que é o intelecto divino se daria em torno dos modos de se preencher um espaço deixando o mínimo de vazios possíveis e com o máximo de figuras possíveis. O espaço, no entanto, não pode ser tomado como um receptáculo preexistente que recebe um mundo. A cada mundo pertencem um espaço, um tempo e uma extensão e não o inverso. Nas palavras de Deleuze, o jogo leibniziano interioriza os jogadores e a própria mesa em que se joga.

Para compreender a relação entre os dois segmentos em que se divide a Utopia de More, passamos do problema geopolítico da separação do território de Utopia do continente ao problema do cálculo diferencial e ao ponto de vista sobre a variação. Trata-se aqui de pensar o deslocamento espacial que caracteriza o pensamento distópico a partir da afirmação de Leibniz, no $\$ 6$ do Discurso de metafísica, de que o mundo escolhido por Deus entre os infinitos possíveis se assemelha a uma curva. Se o traço dessa curva não exprime uma evolução no tempo, mas o contorno do mundo, suas inflexões permitem pensar o mundo atual a partir das tangentes a que correspondem os possíveis, no cálculo diferencial, ou a partir das anamorfoses que se oferecem a um ponto de vista diante da curvatura de uma lente ou de um espelho, conforme os conceitos da óptica. Os massacres e as pilhagens que caracterizam o processo de colonização do continente americano encontrariam, assim, uma forma de expressão no movimento radical de espacialização em que consiste a construção mecânica de uma curva. Mary Shelley, H. G. Wells e Philip K. Dick são herdeiros do que poderíamos chamar de mitologia dos brancos acerca da gemelaridade impossível.

\section{REFERÊNCIAS}

BOYER, C. The history of the calculus and ist conceptual development. Nova Iorque: Dover Publications, 1949 .

DELEUZE, G. A dobra: Leibniz e o barroco. 6. ed. Campinas: Papirus, 2012.

JAMESON, F. Archaelogies of the future: the desire called Utopia and other science fictions. Londres ; Nova Iorque: Verso, 2005. 
KENDRICK, C. “More's Utopia and uneven development”. Boundary, v. 13, n. 2, p. 233-266.

LEIBNIZ, G. W. Discurso de metafísica e outros textos. São Paulo: Martins Fontes, 2004b. Essais de Théodicée: sur la bonté de Dieu, la liberté de l'homme et l'origine du mal. Paris : GF Flammarion, 1969.

LÉVI-STRAUSS, C. História de Lince. São Paulo: Companhia das Letras, 1993.

MORE, T. Utopia. 3. ed. São Paulo: Ed. WMF Martins Fontes, 2009. 